\title{
Effect of Beryllium Aluminum Cyclosilicate on Thermal Expansion Behavior of Al-Based Composites
}

\author{
V. Bharat'1, B. Durga Prasad1, K. Venkateswarlu² \\ ${ }^{1}$ Department of Mechanical Engineering, JNTUA, Anantapuramu, India \\ ${ }^{2}$ CSIR-National Aerospace Laboratories, Bangalore, India \\ Email: bharat_v79@yahoo.com
}

How to cite this paper: Bharat, V., Prasad, B.D. and Venkateswarlu, K. (2017) Effect of Beryllium Aluminum Cyclosilicate on Thermal Expansion Behavior of Al-Based Composites. Journal of Minerals and Materials Characterization and Engineering, 5, 140152.

https://doi.org/10.4236/jmmce.2017.53012

Received: February 23, 2017

Accepted: May 23, 2017

Published: May 26, 2017

Copyright $\odot 2017$ by authors and Scientific Research Publishing Inc. This work is licensed under the Creative Commons Attribution International License (CC BY 4.0).

http://creativecommons.org/licenses/by/4.0/

c) (i) Open Access

\begin{abstract}
Beryllium aluminum cyclosilicate, an ore of beryllium was reinforced in Aluminum matrix to fabricate Al-beryl composites using powder metallurgy. Effect of the content of beryllium aluminum cyclosilicate on microstructural hardness and thermal expansion was studied. The coefficient of thermal expansion of Al-beryl composite was measured in the temperature range between $50^{\circ} \mathrm{C}$ to $360^{\circ} \mathrm{C}$ using dilatometer and was theoretically studied using thermo-elastic models, and these models were used to explain abnormalities observed experimentally. The hardness of Al-beryl metal matrix composites increased with the increase in beryl percentage. Vacuum sintering of Al-beryl metal matrix composites at $600^{\circ} \mathrm{C}$ inhibited excellent bonding between the matrix and the particulate increasing the strength of the composite. The result shows the CTE significantly increased with increasing temperature but decreased with increasing reinforcement. At higher temperatures, CTE of Al-beryl metal matrix composites with $5 \mathrm{wt} \%, 10 \mathrm{wt} \%$ and $15 \mathrm{wt} \%$ of beryllium aluminum cyclosilicate was $21 \mathrm{ppm} / \mathrm{K}, 18.2 \mathrm{ppm} / \mathrm{K}$, and $16.8 \mathrm{ppm} / \mathrm{K}$. The CTE values were found to be comparable with theoretical results. The turner model showed conformance with experimental results, was well suited to the experimental results.
\end{abstract}

\section{Keywords}

Al-Beryl MMCs, Powder Metallurgy, Hardness, Coefficient of Thermal Expansion (CTE), Thermo-Elastic Models

\section{Introduction}

Metal matrix composites (MMCs) have been undergoing various technological advances and emerged as a class of materials suitable for structural, thermal and 
wear applications. They exhibit significant improvement in physical and mechanical properties compared with monolithic materials in strength, elastic modulus, fatigue resistance and tribological properties at room and elevated temperatures [1] [2] [3]. Ceramic reinforced MMCs are widely used in spark plug electrodes, rocket nozzles, pistons, bearings, cutting tools where the coefficient of thermal expansion (CTE) plays an important role in the performance of these components [4] [5]. The CTE of MMCs can be tailored by varying the type and volume fraction of reinforcement in the composite [6]. A low CTE and high thermal conductivity are desirable properties for applications related to heat dissipation in electronic appliances like large scale integration devices and space structures [7] [8]. Materials with low density are used in operations that require superior performance, especially in aerospace, marine and automobile applications. Aluminum MMCs are widely used due to its low weight to strength ratio [3]. Aluminium MMCs (AMMCs) reinforced with hard ceramic particles find potential applications in engine blocks, pistons, brake rotors and suspension components [9]. When exposed to high temperatures, these composites will have good geometric stability where CTE plays a key role [10]. With this objective, an attempt has been made to study the CTE behavior of the A1 matrix reinforced with beryl particles in the temperature range of $30^{\circ} \mathrm{C}$ to $350^{\circ} \mathrm{C}$.

The coefficient of linear thermal expansion (CTE or $\alpha$ ) is a material property that is indicative of the extent to which a material expands upon heating [11]. Over small temperature ranges, the thermal expansion of uniform linear objects will be proportional to temperature change [12]. Studies on thermal expansion behavior of MMCs are scanty. T. H. Nam et al. focused on the effect of size and shape of the reinforcement, elastic properties of matrix and reinforcement on CTE [13]. M. E. Smagorinski et al. found that with the addition of ceramic particles, there was a reduction in CTE of composites and increase in thermal conductivity [14]. The CTE of a composite material depends on various parameters like type of reinforcement, the volume fraction of the reinforcements, properties of the matrix and reinforcement and porosity levels [15] [16] [17]. Thermal expansion behavior of the composites also depends on the stresses developed internally between the matrix and the reinforcement [18].

There are three several types of coefficients of thermal expansion: linear, superficial and volumetric CTEs. The measurement of the linear CTE is denoted by $\alpha$ and is given by

$$
\alpha=\Delta L / L_{0} \Delta T
$$

where, $L_{0}$ is the original length of the sample, and $\Delta L$, is the change in length and $\Delta T$ is temperature interval. The superficial CTE is denoted by $\gamma$ and is defined as

$$
\gamma=\Delta A / A_{0} \Delta T
$$

where, $A_{0}$ is the original area of the specimen, and $\Delta A$ is the change in area over a temperature interval $\Delta T$. The cubic or volumetric CTE, $\beta$, is defined as

$$
\beta=\Delta V / V_{0} \Delta T
$$


where, $V_{0}$ is the initial volume, and $\Delta V$ is the change of the volume over a temperature range $\Delta T$. The $\gamma$ and $\beta$ are related to the linear CTE by

$$
\alpha=\gamma / 2=\beta / 3
$$

Many analytical models developed by Kerner, Turner, and Schapery bounds [13] are used to predict thermal expansion behavior of composites. These thermoelastic models are having been used to understand the dependence of CTE on weight fraction of CTE within elastic limits. These models do not consider the effect of porosity and cannot predict CTE beyond elastic limit [19].

In the present study, an attempt was made to study linear CTE of Al-beryl MMCs and its effect on reinforcement percentage of beryl particles and temperature. The CTE of Al-beryl MMCs was measured between $30^{\circ} \mathrm{C}$ and $350^{\circ} \mathrm{C}$ by a high precision dilatometer, and the experimental results were compared with thermo-elastic models, and an appropriate model was proposed to predict CTE of Al-beryl MMCs.

\section{Experimental Procedure}

\subsection{Material Selection}

First, commercially available pure aluminum, hereby referred as $\mathrm{Al}$, was selected as a base metal. Al has a low density with good corrosion resistance, strength, ductility and improved tribological properties. The chemical composition of commercially available pure $\mathrm{Al}$ is given in Table 1 .

Beryl used as reinforcement, is a ceramic material for high-temperature applications because of its high melting point, lower density and capacity to retain high strength at elevated temperatures. Beryl with chemical formula $\mathrm{Be}_{3} \mathrm{Al}_{2} \mathrm{Si}_{6} \mathrm{O}_{18}$ with a hexagonal crystal structure is a naturally occurring ceramic particle. It has a specific gravity of 2.6 to 2.8 with a hardness of 7.5 to 8 on Mohs scale. Beryl does not have a sharp melting point but softens between temperatures $1475^{\circ} \mathrm{C}$ and $1550^{\circ} \mathrm{C}$ and has a low CTE of $2.6 \times 10^{-6} / \mathrm{K}$ [20]. In the present study beryl particles used were nearly spherical in shape having a particle size of $38 \mu \mathrm{m}$ and $108 \mu \mathrm{m}$. The chemical composition of beryl particles is given in Table 2. The chemical compositions of the matrix and the reinforcement are determined using energy dispersive X-ray (EDX) microanalysis using electron microprobe analyzer JXA-A230.

\subsection{Specimen Preparation}

The Beryl was procured in the form of stones and was crushed to powder form

Table 1. Chemical composition of Al by weight percentage.

\begin{tabular}{ccc}
\hline $\mathrm{Si}$ & $\mathrm{Fe}$ & $\mathrm{Al}$ \\
\hline 0.14 & 0.16 & Balance
\end{tabular}

Table 2. Chemical composition of beryl by weight percentage.

\begin{tabular}{ccccccccc}
\hline $\mathrm{SiO}_{2}$ & $\mathrm{Al}_{2} \mathrm{O}_{3}$ & $\mathrm{BeO}$ & $\mathrm{Fe}_{2} \mathrm{O}_{3}$ & $\mathrm{CaO}$ & $\mathrm{MgO}$ & $\mathrm{Na}_{2} \mathrm{O}$ & $\mathrm{K}_{2} \mathrm{O}$ & $\mathrm{MnO}$ \\
\hline 65.41 & 17.94 & 12.3 & 0.8 & 1.34 & 0.48 & 0.55 & 0.004 & 0.05 \\
\hline
\end{tabular}


using a ball mill. A proper ball to powder ratio was maintained to avoid powder agglomeration [21]. Crushed beryl particles were sieved to segregate into numerous sizes. Particle Size Analysis (PSA) was carried out after sieving. Fabrication of Al-Beryl MMCs was carried out by varying the size of the beryl particles and beryl content. Beryl particles of sizes $108 \mu \mathrm{m}$ (coarse) and $38 \mu \mathrm{m}$ (fine) were used to fabricate Al-Beryl MMCs. Percentage of beryl content was varied by $5 \%$, $10 \%$ and $15 \%$ by weight. The technique used to produce AMCs by powder metallurgy (P/M) process is like those used for processing of un-reinforced materials. In this process, the matrix powder with reinforcement material and binder after blending is fed into a die of the desired shape. Cold isostatic pressing is used to obtain a green compact. These compacted pellets were sintered using Microwave sintering at a temperature of $500^{\circ} \mathrm{C}$. Sometimes it becomes necessary to maintain the consolidation temperature slightly above the solidus to minimize deformation stress, and to avoid the damage of particles or whiskers. Sintering of Al-beryl MMCs is more energy efficient than for most other P/M materials due to the relatively low sintering temperatures. Specimens for CTE testing having a diameter of $8 \mathrm{~mm}$ and length $20 \mathrm{~mm}$ were machined from the prepared MMCs. To verify the reproducibility of data, three samples of each composite were tested under the same condition.

\subsection{CTE Testing Procedure}

CTE is measured as per ASTM E228 standards using tube dilatometer (Model: BSPIL-MTR-DM). A dilatometer consists of an oven, support to hold the samples, thermocouples and LVDT sensors. Samples can be heated up to $1200^{\circ} \mathrm{C}$. The sample holder and push rod can accommodate samples up to $60 \mathrm{~mm}$ long. Temperature is recorded with K-type thermocouples located at the support for the measurement of sample temperature and at the center of the oven which is used to detect and control the heating temperature. The accuracy of CTE measured by this instrument is equal to $\pm 0.1 \times 10^{-6} / \mathrm{K}$.

\section{Analytical Thermo-Elastic Models}

Before A particulate composite is a homogeneous material having a uniform distribution of the particles in the matrix. Volume fractions of the two phases are $\mathrm{V}_{1}$ and $\mathrm{V}_{2}$. The CTE of the MMCs is depended on several factors like matrix, size, and shape of the particles, distribution, type of particles and the microstructure of the composite. For the prediction of CTE of MMCs many models based on thermo-elastic energy principles were used such as Kerner, Schapery, and Turner models [22]. The thermal expansion results of MMCs obtained experimentally will be different from values obtained by the simple rule of mixtures. This is due to the significant difference between CTE values of the reinforcement and the matrix [23]. The degree of constraint is also dependent on the nature of the reinforcement. Many models have been proposed to predict the coefficients of thermal expansion (CTE) of particulate composites.

The following assumptions are made during the calculation of CTE using 
thermo-elastic models:

a) The bonding between $\mathrm{Al}$ matrix and the beryl particulates are perfect, and no chemical interactions are allowed between the matrix and the particle.

b) The properties of the constituents do not change with temperature.

c) Poisson's ratios of the components are not very different.

\subsection{Kerner Model}

The composites are isotropic and homogeneous. The Kerner model considers the particles as spherical in shape and discontinuous. CTE of a composite consisting of spherical particles dispersed in a matrix is given by

$$
\alpha_{c}=\alpha_{p} v_{p}+\alpha_{m} v_{m}+\left(\alpha_{p}-\alpha_{m}\right) v_{p} v_{m}\left[\frac{\frac{1}{K_{m}}+\frac{1}{K_{p}}}{\frac{V_{m}}{K_{p}}+\frac{V_{p}}{K_{m}}+\frac{3}{4 G_{m}}}\right]
$$

where $\alpha$ is the CTE of the component and $v$ is the volume fraction. The subscripts $m, p$, and $c$ refer to the matrix, particle, and composite, respectively. $G$ is the shear modulus, which is given by,

$$
G=\frac{E}{2(1+v)}
$$

$K$ is the bulk modulus of the of the composite, which is related to Young's modulus $E$ and the Poisson's ratio m of isotropic materials by

$$
K=\frac{E}{3(1-2 v)}
$$

\subsection{Schapery Bounds}

Schapery bounds assume that the composite behaves as isotropic material and helps to determine CTE by considering the stress interaction between the matrix and the reinforcement. This model gives upper and lower bounds for the thermal expansion coefficient.

Upper bound is given by

$$
\alpha_{c}^{+}=\alpha_{p} v_{p}+\alpha_{m} v_{m}+\left[\frac{4 G_{m}}{K_{c}}\right]\left[\frac{\left(K_{c}-K_{p}\right)\left(\alpha_{m}-\alpha_{p}\right) V_{p}}{4 G_{m}+3 K_{p}}\right]
$$

Lower bound is given by

$$
\alpha_{c}^{-}=\alpha_{p} v_{p}+\alpha_{m} v_{m}+\left[\frac{4 G_{m}}{K_{c}}\right]\left[\frac{\left(K_{c}-K_{p}\right)\left(\alpha_{p}-\alpha_{m}\right) V_{m}}{4 G_{p}+3 K_{m}}\right]
$$

\subsection{Turner Model}

Turner model considers that internal stresses developed between the matrix and the reinforcement are not enough to disrupt the composite. The sum of the internal forces can be equated to zero, and an expression of the CTE of the composite is obtained as: 


$$
\alpha_{c}=\left[\frac{\alpha_{m} v_{m} k_{m}+\alpha_{p} v_{p} k_{p}}{v_{p} k_{p}+v_{m} k_{m}}\right]
$$

Turner model considers that there is a homogeneous strain throughout the composite, i.e., strain at every component in the composite changes in the same rate as a composite. Turner model assumes that uniform hydrostatic stresses exist in the phases and shear deformation is negligible.

\section{Results and Discussion}

\subsection{Particle Size Analysis}

Particle size influences processing conditions, microstructure, and properties of the composite. The size and shape of particles influences parameters like green strength, compressibility, apparent density, agglomeration, flow rate, porosity, and sinterability. Particle size analysis of beryl powders is carried out by laser diffraction technique using Mastersizer 2000, which confirms to ISO13320-1 guidelines. The results are shown in Figure 1 and Figure 2. It can be observed from PSA results that the samples collected after sieving were in the range of 108

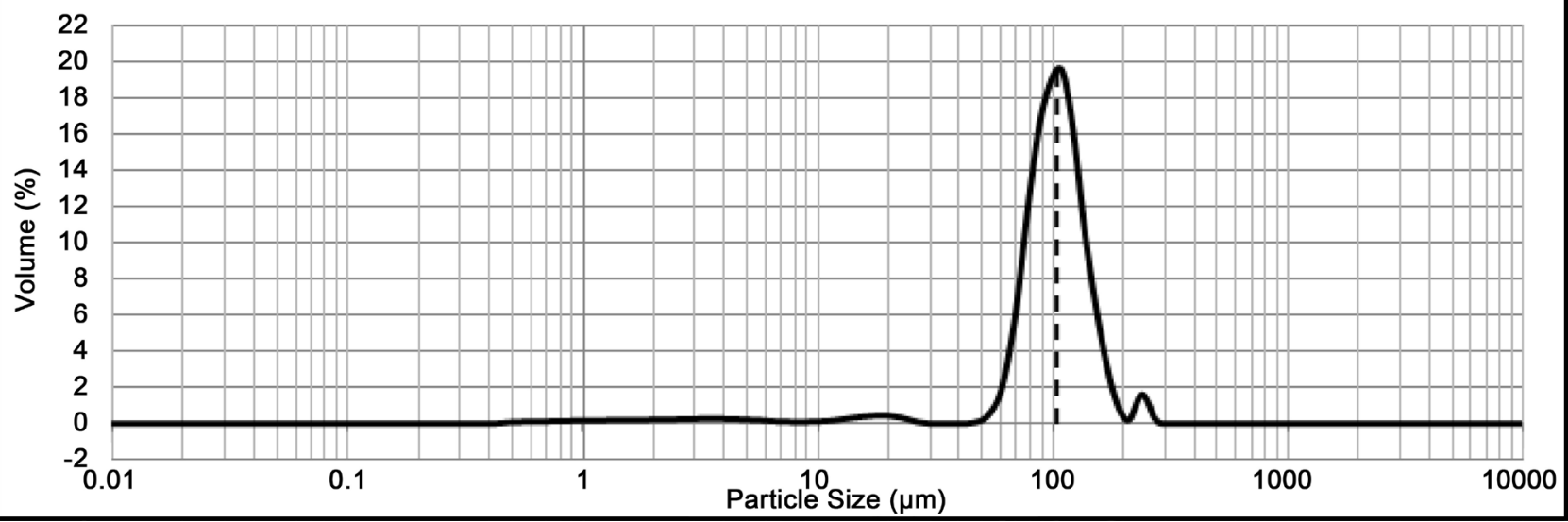

Figure 1. Beryl with average particle size of $\sim 108 \mu \mathrm{m}$.

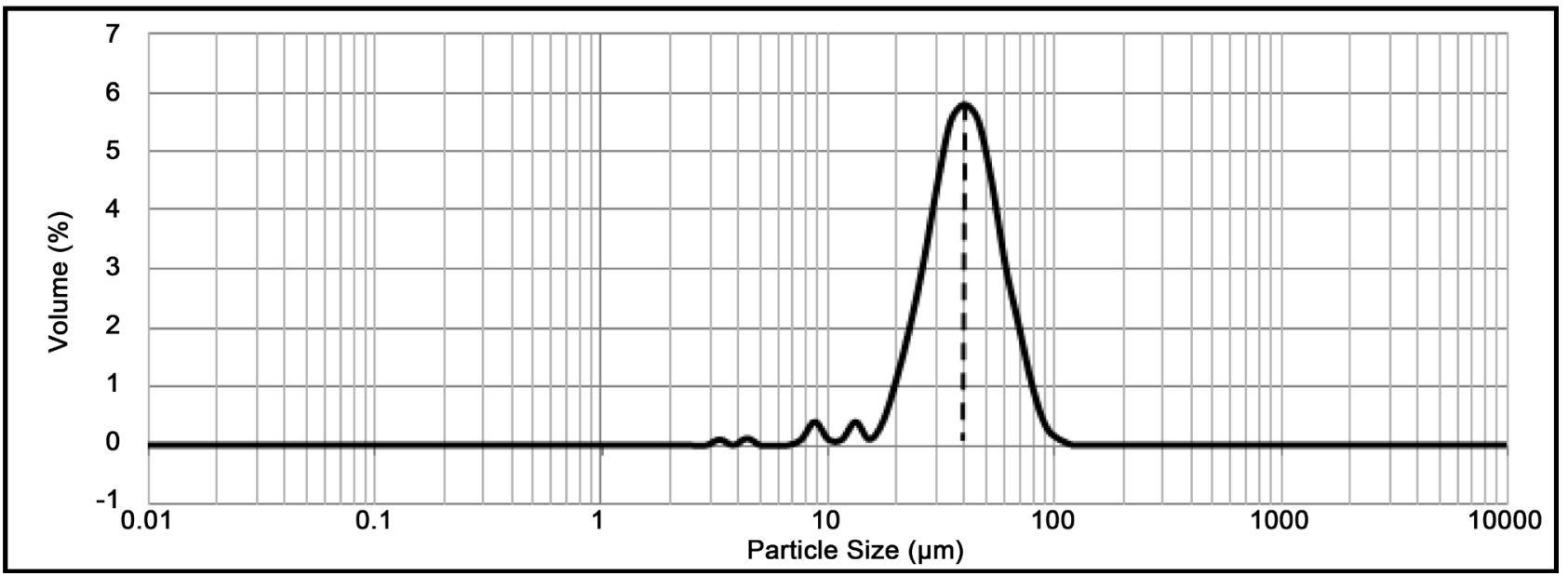

Figure 2. Beryl with average particle size of $\sim 38 \mu \mathrm{m}$. 
$\mu \mathrm{m}$ and $38 \mu \mathrm{m}$.

\subsection{Microstructural Studies}

Scanning electron microscope (SEM) images of $\mathrm{Al}$ powder (Figure 3) shows aluminum particles with of uniform size and there are no flakes present in the powder. SEM images of crushed beryl powders are shown in Figure 4 confirming that there is no particle agglomeration and the shape of the beryl particles was uniform.

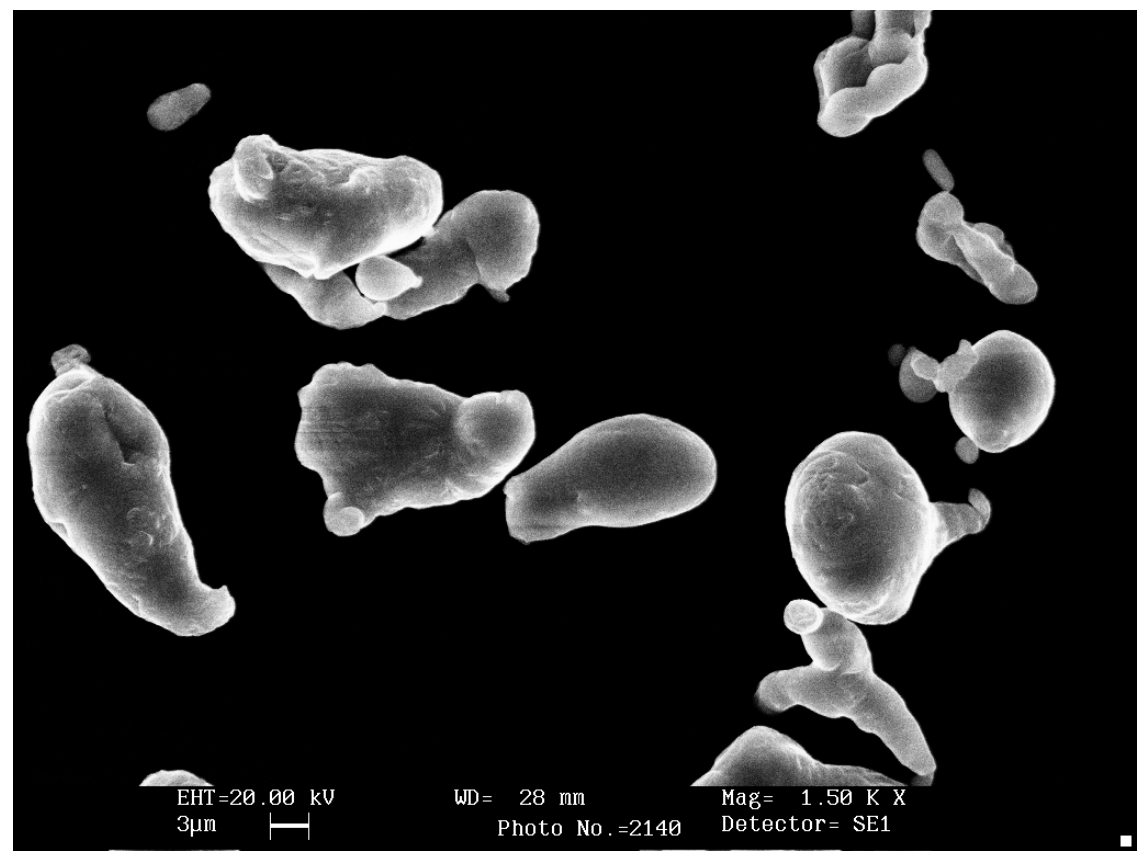

Figure 3. SEM image of Al Powder.

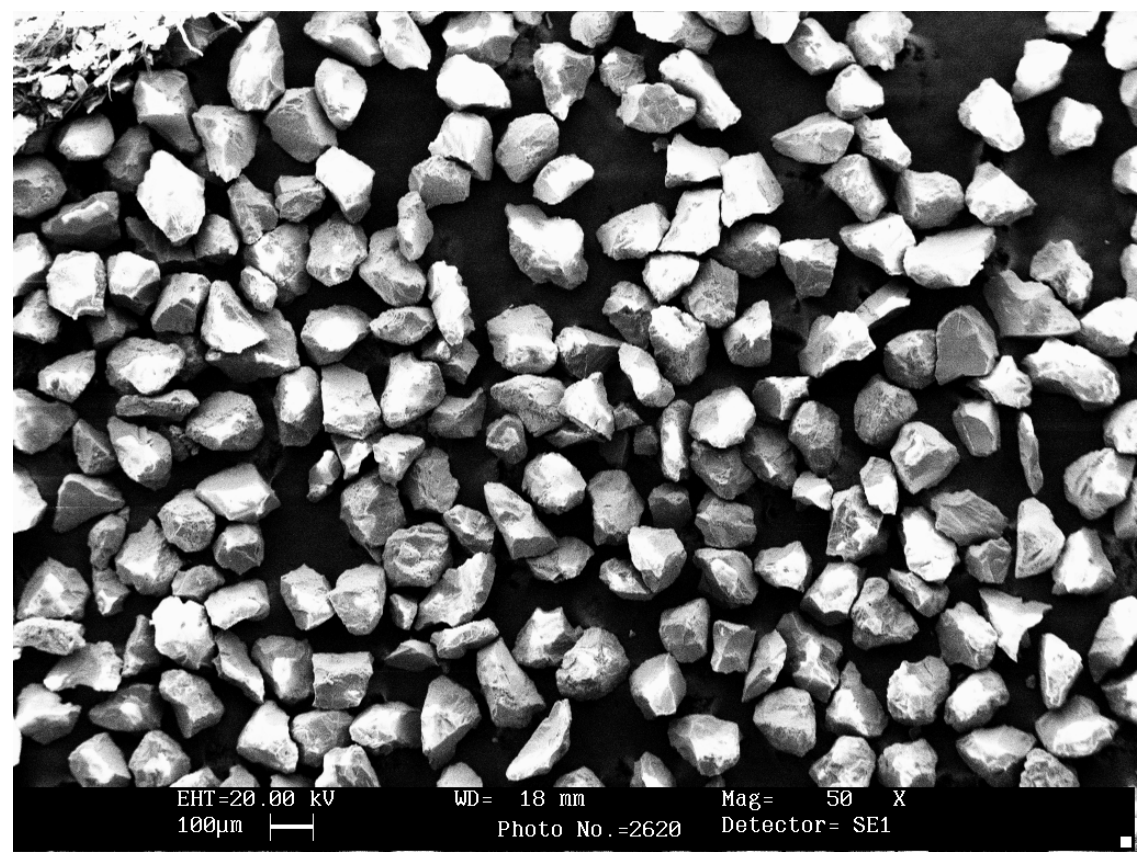

Figure 4. SEM image of beryl Powder. 


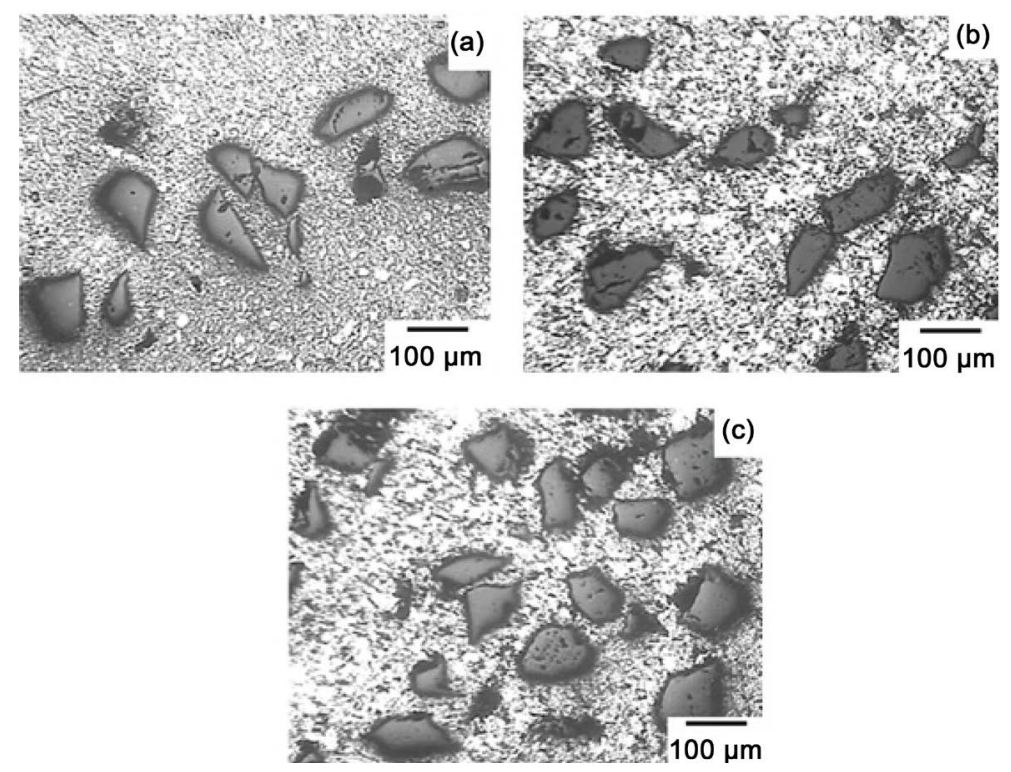

Figure 5. Optical images of Al-Beryl MMCs at X 500 (a) 5\% Beryl, (b) 10\% Beryl, (c) 15\% Beryl.

Micrographs of the transverse section of Al-beryl MMCs are shown in Figure 5. The distribution appears to be reasonably uniform and homogenous. It was observed that for higher percentages of reinforcement, the particles are aligned slightly more in the longitudinal direction. A very good interfacial bond between the beryl particulates and $\mathrm{Al}$ matrix was obtained. As beryl is ceramic in nature and is chemically inert at higher temperatures, it is observed that in the microstructure that no compound formation is found at the interfacial area.

\subsection{Hardness}

The Vickers hardness test was performed to determine themicro hardness of Alberyl MMCs with a load of $100 \mathrm{~g}$ for the duration of $10 \mathrm{~s}$ as per ASTM E92 standards. The hardness is tested at three separate locations on the specimen, and the average of 3 readings was taken for a single specimen. The hardness of Al-beryl composites, by varying reinforcement content from $5 \%$ by wt. to $15 \%$ by wt. and the effect of sintering temperature and beryl particle size is presented in Figure 6(a) \& Figure 6(b). With the increase in the beryl content, it is evident that the hardness of Al-beryl MMCs. The hardness of Al-beryl MMCs increased by $30 \%$ by varying beryl content from $5 \%$ to $15 \%$ by wt. The size of beryl particle has a significant impact on the hardness of Al-beryl MMCs. Al-beryl MMCs with finer beryl particles $(38 \mu \mathrm{m})$ exhibited higher hardness when compared to Al-beryl MMCs with coarse beryl particles $(108 \mu \mathrm{m})$. This is because dislocation density is much higher in the matrix reinforced with fine beryl particles than in coarse beryl particles. The sintering temperature of $600^{\circ} \mathrm{C}$ resulted in higher hardness of the composite which accounts to almost $0.9 \mathrm{Tm}$ of $\mathrm{Al}$.

\subsection{Coefficient of Thermal Expansion}

The thermal expansion coefficients of Al-beryl MMCs with different weight 

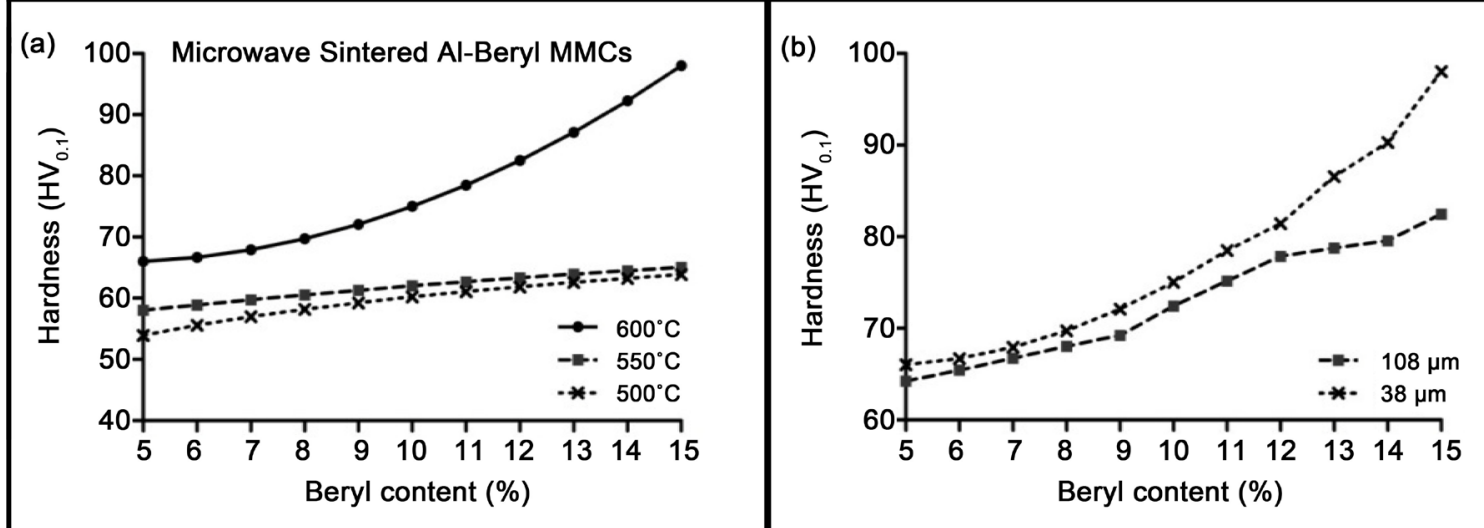

Figure 6. Hardness of Al-beryl MMCs (a) effect of sintering temperature (b) effect of particle size.

Table 3. Chemical composition of Al by weight percentage.

\begin{tabular}{ccccc}
\hline \multicolumn{5}{c}{ Beryl Reinforcement (wt\%) } \\
\hline Temperature $\left({ }^{\circ} \mathrm{C}\right)$ & $0\left(10^{-6} \mathrm{~K}^{-1}\right)$ & $5 \%\left(10^{-6} \mathrm{~K}^{-1}\right)$ & $10 \%\left(10^{-6} \mathrm{~K}^{-1}\right)$ & $15 \%\left(10^{-6} \mathrm{~K}^{-1}\right)$ \\
\hline 60 & 23.1 & 1.90 & 1.80 & 0.50 \\
80 & 23.8 & 7.80 & 2.20 & 1.30 \\
100 & 24.2 & 10.1 & 5.20 & 2.60 \\
120 & 24.6 & 11.5 & 7.40 & 5.50 \\
140 & 24.9 & 13.0 & 9.40 & 7.80 \\
160 & 25.2 & 14.6 & 12.0 & 9.50 \\
180 & 25.5 & 15.5 & 12.9 & 11.2 \\
200 & 25.7 & 15.8 & 13.7 & 12.6 \\
220 & 26.1 & 17.0 & 14.8 & 13.3 \\
240 & 26.6 & 17.3 & 15.5 & 13.6 \\
260 & 27.4 & 18.2 & 16.0 & 14.5 \\
280 & 27.6 & 18.9 & 16.8 & 15.0 \\
300 & 27.7 & 19.4 & 17.3 & 15.5 \\
320 & 28.5 & 20.2 & 17.5 & 15.8 \\
340 & 29.0 & 20.7 & 17.8 & 16.0 \\
360 & 29.4 & 21.0 & 18.2 & 16.8 \\
\hline
\end{tabular}

percentage of are shown in Table 3. It can be observed that as the weight percentage of reinforcement increases from $5 \%$ to $15 \%$ there is a drastic reduction in CTE and it was evident from the results that CTE of Al-beryl MMC is less compared to CPAl. The CTE of the CPAl and Al-beryl MMCs with variation in temperature and reinforcement percentages are shown in Figure 7. The CTE of both $\mathrm{CPAl}$ and $\mathrm{Al}-\mathrm{Beryl} \mathrm{MMC}$ was found to increase with an increase in temperature.

Young's modulus and CTE of pure aluminum and beryl at different temperatures are used to determine theoretical values of CTE using thermo-elastic models. Thermal expansion coefficients of Al-beryl MMCs obtained from dilatometry are plotted together with the values obtained from thermo-elastic models given in the previous section, as shown in Figure 8. 


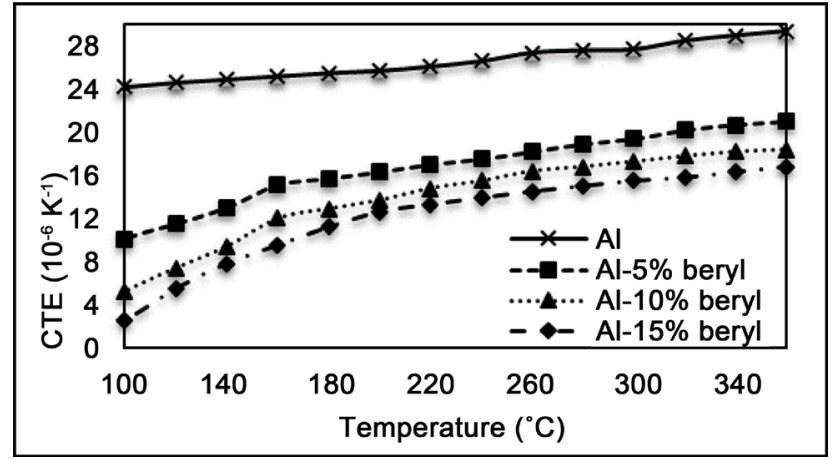

Figure 7. CTE vs. Temperature of Al-beryl MMCs.
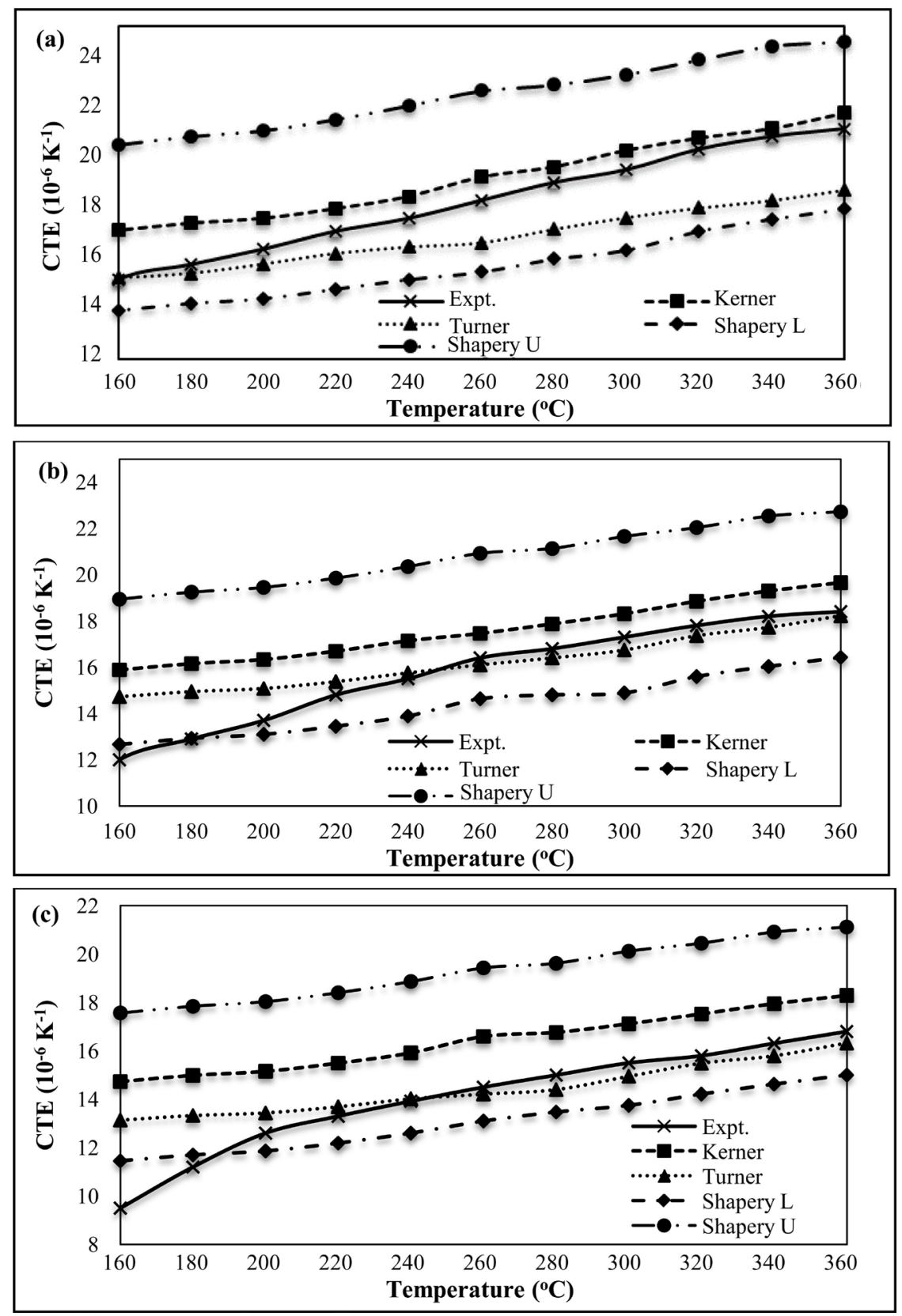

Figure 8. Comparison of experimental results of CTE with thermo-elastic models: (a) $5 \%$ reinforcement, (b) 10\% reinforcement, (c) 15\% reinforcement. 


\section{Conclusions}

Al-beryl MMCs with $5 \%$ to $15 \%$ by weight percentage of beryl were successfully fabricated using powder metallurgy process. The following conclusions can be drawn from this study.

- The thermal expansion coefficients of Al-beryl MMCs decrease with the increase in beryl content between the temperature ranges $0^{\circ} \mathrm{C}$ to $360^{\circ} \mathrm{C}$. Further, the CTE values of Al-beryl MMCs remain uniform over a large temperature range which is an advantage.

- Thermo-elastic models like Kerner model, Turner model, Schapery upper and lower bounds are used to evaluate and predict CTE of Al-beryl MMCs. The experimental values of thermal expansion of Al-beryl MMC are compared with thermo-elastic models, and the results fairly agree with those predicted by the Turner model at higher temperatures. Kerner model agrees with experimental values only at lower reinforcement percentages but overestimates the CTE values at $10 \%$ and $15 \%$ reinforcement of beryl by weight.

- The discrepancy between the theoretical values and experimental values of the CTE could be due to the anisotropic nature of beryl with the different coefficients of expansion in various crystallographic directions and the lack of perfect bonding between the metal matrix and beryl particulates.

\section{References}

[1] Yuan, L., Han, J., Liu, J. and Jiang, Z. (2016) Mechanical Properties and Tribological Behavior of Aluminum Matrix Composites Reinforced with In-Situ AlB2 Particles. Tribology International, 98, 41-47. https://doi.org/10.1016/j.triboint.2016.01.046

[2] Stojanović, B., Babić, M., Veličković, S. and Blagojević, J. (2016) Tribological Behavior of Aluminum Hybrid Composites Studied by Application of Factorial Techniques. Tribology Transactions, 59, 522-529. https://doi.org/10.1080/10402004.2015.1091535

[3] Singh, J. and Chauhan, A. (2016) Characterization of Hybrid Aluminum Matrix Composites for Advanced Applications-A Review. Journal of Materials Research and Technology, 5, 159-169. https://doi.org/10.1016/j.jmrt.2015.05.004

[4] Vogiatzis, C.A. and Skolianos, S.M. (2016) On the Sintering Mechanisms and Microstructure of Aluminium-Ceramic Cenospheres Syntactic Foams Produced by Powder Metallurgy Route. Composites Part A: Applied Science and Manufacturing, 82, 8-19. https://doi.org/10.1016/j.compositesa.2015.11.037

[5] Ashwath, P. and Xavior, M.A. (2016) Effect of Ceramic Reinforcements on Microwave Sintered Metal Matrix Composites. Materials and Manufacturing Processes, 16. https://doi.org/10.1080/10426914.2016.1244851

[6] Sideridis, E. (2016) The Influence of Particle Distribution and Interphase on the Thermal Expansion Coefficient of Particulate Composites by the Use of a New Model. Composite Interfaces, 23, 231-254.

https://doi.org/10.1080/09276440.2016.1132097

[7] Siddiqui, M.S. and Fowler, D.W. (2015) A Systematic Optimization Technique for the Coefficient of Thermal Expansion of Portland Cement Concrete. Construction and Building Materials, 88, 204-211.

https://doi.org/10.1016/j.conbuildmat.2015.04.008

[8] Zhou, C., Zhang, Q., Liu, Y., Wu, G. and Liu, S. (2014) Thermal Expansion of 
$\mathrm{Y}_{2} \mathrm{~W}_{3} \mathrm{O}_{12} / \mathrm{Al}$ Metal Matrix Composites. Materials Research Innovations, 18, S4-490S4-494. https://doi.org/10.1179/1432891714z.000000000837

[9] Pandi, G. and Muthusamy, S. (2012) A Review on Machining and Tribological Behaviors of Aluminium Hybrid Composites. Procedia Engineering, 38, 1399-1408. https://doi.org/10.1016/j.proeng.2012.06.174

[10] Sidhu, S.S., Kumar, S. and Batish, A. (2015) Metal Matrix Composites for Thermal Management: A Review. Critical Reviews in Solid State and Materials Sciences, 41, 132-157. https://doi.org/10.1080/10408436.2015.1076717

[11] Sharma, N.K., Misra, R.K. and Sharma, S. (2014) Thermal Expansion Behavior of $\mathrm{Ni}-\mathrm{Al}_{2} \mathrm{O}_{3}$ Composites with Particulate and Interpenetrating Phase Structures: An Analysis Using Finite Element Method. Computational Materials Science, 90, 130136. https://doi.org/10.1016/j.commatsci.2014.04.008

[12] Nawab, Y., Jacquemin, F., Casari, P., Boyard, N., Borjon-Piron, Y. and Sobotka, V. (2013) Study of Variation of Thermal Expansion Coefficients in Carbon/Epoxy Laminated Composite Plates. Composites Part B: Engineering, 50, 144-149. https://doi.org/10.1016/j.compositesb.2013.02.002

[13] Nam, T.H., Requena, G. and Degischer, P. (2008) Thermal Expansion Behaviour of Aluminum Matrix Composites with Densely Packed SiC Particles. Composites Part A: Applied Science and Manufacturing, 39, 856-865. https://doi.org/10.1016/j.compositesa.2008.01.011

[14] Smagorinski, M.E. and Tsantrizos, P.G. (2013) Development of Light Composite Materials with Low Coefficients of Thermal Expansion. Materials Science and Technology, 16, 853-861. https://doi.org/10.1179/026708300101508568

[15] Huber, T., Degischer, H.P., Lefranc, G. and Schmitt, T. (2006) Thermal Expansion Studies on Aluminium-Matrix Composites with Different Reinforcement Architecture of SiC Particles. Composites Science and Technology, 66, 2206-2217. https://doi.org/10.1016/j.compscitech.2005.12.012

[16] Zhang, Q., Wu, G., Jiang, L. and Chen, G. (2003) Thermal Expansion and Dimensional Stability of Al-Si Matrix Composite Reinforced with High Content SiC. Materials Chemistry and Physics, 82, 780-785. https://doi.org/10.1016/j.matchemphys.2003.07.001

[17] Arpón, R., Molina, J.M., Saravanan, R.A., García-Cordovilla, C., Louis, E. and Narciso, J. (2003) Thermal Expansion Behaviour of Aluminium/SiC Composites with Bimodal Particle Distributions. Acta Materialia, 51, 3145-3156. https://doi.org/10.1016/S1359-6454(03)00126-5

[18] Karadeniz, Z.H. and Kumlutas, D. (2007) A Numerical Study on the Coefficients of Thermal Expansion of Fiber Reinforced Composite Materials. Composite Structures, 78, 1-10. https://doi.org/10.1016/j.compstruct.2005.11.034

[19] Ran, Z., Yan, Y., Li, J., Qi, Z. and Yang, L. (2014) Determination of Thermal Expansion Coefficients for Unidirectional Fiber-Reinforced Composites. Chinese Journal of Aeronautics, 27, 1180-1187. https://doi.org/10.1016/j.cja.2014.03.010

[20] Zaki, E.E., Ismail, Z.H., Daoud, J.A. and Aly, H.F. (2005) Extraction Equilibrium of Beryllium and Aluminum and Recovery of Beryllium from Egyptian Beryl Solution Using CYANEX 921. Hydrometallurgy, 80, 221-231.

https://doi.org/10.1016/j.hydromet.2005.07.009

[21] Zhang, C., Cai, Z., Wang, R., Peng, C., Qiu, K. and Wang, N. (2016) Microstructure and Thermal Properties of Al/W-Coated Diamond Composites Prepared by Powder Metallurgy. Materials \& Design, 95, 39-47. https://doi.org/10.1016/j.matdes.2016.01.085

[22] Guinovart-Díaz, R., Sabina, F.J., Bravo-Castillero, J. and Rodríguez-Ramos, R. 
(2005) Thermoelastic Expressions for the Effective Coefficients of a Fibre-Reinforced Composite. Philosophical Magazine, 85, 4181-4199.

https://doi.org/10.1080/14786430500363346

[23] Roy, S.K., Ghosh, S.K., Ghosh, A. and Ramanathan, S. (2014) Microstructure Characterization and Thermal Expansion Behaviour of Interpenetrating Alumina/Aluminium Composites. Transactions of the Indian Ceramic Society, 64, 137-142. https://doi.org/10.1080/0371750X.2005.11012203

Submit or recommend next manuscript to SCIRP and we will provide best service for you:

Accepting pre-submission inquiries through Email, Facebook, LinkedIn, Twitter, etc. A wide selection of journals (inclusive of 9 subjects, more than 200 journals) Providing 24-hour high-quality service User-friendly online submission system Fair and swift peer-review system Efficient typesetting and proofreading procedure Display of the result of downloads and visits, as well as the number of cited articles Maximum dissemination of your research work

Submit your manuscript at: http://papersubmission.scirp.org/

Or contact jmmce@scirp.org 